\title{
DÜBLIN
}

Technological University Dublin

ARROW@TU Dublin

Articles

School of Physics \& Clinical \& Optometric

Science

2014

\section{Progress in Zeolite Synthesis Promotes Advanced Applications}

Moussa Zaarour

University of Caen

Biao Dong

University of Caen

Izabela Naydenova

Technological University Dublin, izabela.naydenova@tudublin.ie

See next page for additional authors

Follow this and additional works at: https://arrow.tudublin.ie/scschphyart

Part of the Chemistry Commons

\section{Recommended Citation}

Zaaeour, M. et al. (2014) Progress in Zeolite Synthesis Promotes Advanced Applications. Microporous and Mesoporous Materials1 Vol. 189, May, pp. 11-21. doi:10.1016/j.micromeso.2013.08.014

This Article is brought to you for free and open access by the School of Physics \& Clinical \& Optometric Science at ARROW@TU Dublin. It has been accepted for inclusion in Articles by an authorized administrator of ARROW@TU Dublin. For more information, please contact arrow.admin@tudublin.ie, aisling.coyne@tudublin.ie, gerard.connolly@tudublin.ie.

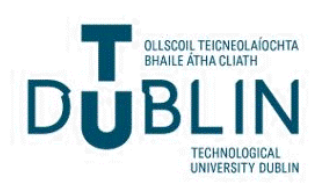




\section{Authors}

Moussa Zaarour, Biao Dong, Izabela Naydenova, Richard Retoux, and Svetlana Mintova

This article is available at ARROW@TU Dublin: https://arrow.tudublin.ie/scschphyart/40 


\title{
Progress in zeolite synthesis promotes advanced applications
}

\author{
Moussa Zaarour ${ }^{a}$, Biao Dong a , Izabela Naydenova ${ }^{\mathrm{b}}$, Richard Retoux ${ }^{\mathrm{c}}$, Svetlana Mintova ${ }^{\mathrm{a}, *}$ \\ ${ }^{a}$ Laboratoire Catalyse \& Spectrochimie, University of Caen, CNRS, 6, boulevard du Maréchal Juin, 14050 Caen Cedex, France \\ ${ }^{\mathrm{b}}$ Centre for Industrial and Engineering Optics, School of Physics, Dublin Institute of Technology, Kevin Street, Dublin 8, Ireland \\ ${ }^{\mathrm{c}}$ CRISMAT, University of Caen, 6, Boulevard du Maréchal Juin, 14050 Caen Cedex, France
}

\section{A R T I C L E I N F O}

Article history:

Received 25 May 2013

Received in revised form 11 August 2013

Accepted 12 August 2013

Available online $\mathrm{xxxx}$

\section{Keywords:}

Synthesis

Nanosized zeolites

Photovoltaic

Medicine

Holographic sensors

\begin{abstract}
A B S T R A C T
This article outlines the importance of zeolite synthesis and their unique physicochemical characteristics promoting advanced applications. The main strategies for preparation of zeolites including organic-template assisted, organic-template free and alternative procedures are considered for synthesis of crystallites offering control and fine-tuning of their properties. Besides, rational design of zeolites with pre-determined structure, porosity, size, morphology, and composition are more viable by studying carefully the chemical and physical parameters controlling the zeolite synthesis and understanding the crystallization mechanism. Finally, a particular attention to the preparation of zeolites with nanosized dimensions and their utilization in innovative applications including photovoltaic, medicine and holographic sensors are presented.
\end{abstract}

(c) 2013 Published by Elsevier Inc.

\section{Introduction}

The well-defined porous structure of zeolites makes them true shape-selective molecular sieves with wide ranging applications in catalysis, ion exchange and adsorption processes [1,2]. Besides the different pore size and shape, the hydrophilic/hydrophobic nature of zeolites renders them as useful selective sorbents and hosts for guest molecules (organic or inorganic) that are stable in gas and liquid phase. In order to control the synthesis process and to obtain zeolites with predetermined properties, significant efforts have been dedicated to the fundamental understanding of the zeolite crystallization process and the influence of numerous variables and their impact on the physicochemical properties of the final product $[3,4]$. Amongst the number of factors controlling the synthesis of zeolites, the most important to be considered are divided in two groups-chemical and physical parameters (Fig. 1).

\subsection{Parameters governing zeolite synthesis}

The chemistry of the initial precursor mixture (gel/suspension) used for the synthesis of zeolites, more precisely the type of the initial sources, molar ratios, type of solvents, templates, additives and presence of seeds are of significant importance [5-7]. Under variation of these parameters, the initial precursor mixtures can appear as dry solid, dense (viscous) gel, liquid gel, milky suspension, or water clear suspension prior hydrothermal treatment

\footnotetext{
* Corresponding author. Tel.: +332 314527 37; fax: +33 231452821 .

E-mail address: svetlana.mintova@ensicaen.fr (S. Mintova).
}

[8-11]. Almost immediate polymerization and depolymerization processes are occurred, and a possible precipitation can follow. The next step involves hydrothermal synthesis of zeolites that are usually performed in closed reacting systems. The high super-saturation within the precursor mixture leads to spontaneous nucleation and controlled crystallization process under low temperature hydrothermal conditions (bellow $200^{\circ} \mathrm{C}$ ). The initial aluminosilicate precursor under the combined action of mineralizing $\left(\mathrm{OH}^{-}, \mathrm{F}^{-}\right)$and structure-directing agents (SDAs) is transformed into crystalline zeolite (Fig. 2). The SDAs could be alkali metal cations $\left(\mathrm{Na}^{+}, \mathrm{K}^{+}, \mathrm{Li}^{+}\right.$, etc.) or positively charged organic molecules, usually tetraalkylammonium cations $\left(\mathrm{TAA}^{+}\right)$. The generally accepted scheme includes the arrangement of $\mathrm{SiO}_{4}{ }^{-}$and $\mathrm{AlO}_{4}{ }^{-}$tetrahedra around charged templating species, i.e. hydrated alkali metal cations or organic molecules (Fig. 2).

Although all the chemical parameters listed above are strictly specified in the preparation of the initial precursor mixtures, still a large number of variables can influence the crystallization of zeolites. Since the zeolites are metastable phases, a fast transformation from less stable to more stable zeolites can occur under very small changes in the synthesis procedure. Therefore, very specific precursor materials have to be used in order to stimulate the formation of a certain zeolite phase. For example, the dissolution degree of silica or alumina sources has a major influence on the formation of precursor species with different $\mathrm{Si} / \mathrm{Al}$ ratio and size that will be easily converted into target zeolite phase. In contrast, the viscous gels prepared by mixing of slow or not completely dissolved initial materials would result in inhomogeneous reactions that would generate a mixture of several crystalline phases or 


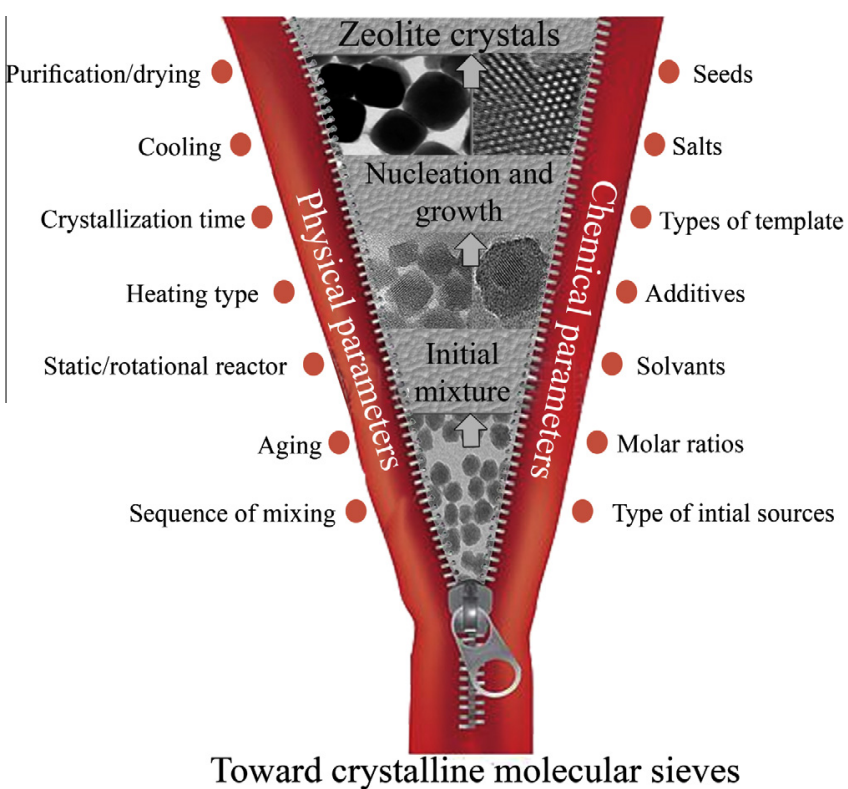

Fig. 1. Main parameters governing zeolite synthesis.

inter-grown crystallites. Recent experiments have demonstrated the possibility to capture highly metastable zeolite (EMT-type) via tuning the chemical composition of the precursor suspension. By exploring the very early stages of zeolite formation, it is possible to favor kinetically the nucleation of desired zeolite and thus to avoid the use of organic structure directing agents [12,13].

As mentioned above, organic structure directing agents are commonly employed to form and stabilize the framework of molecular sieves [14,15]. Many organic templates have been designed and used to obtain new framework types or to extend the composition of a known zeolite beyond the limits imposed by the nature. The chemical nature, shape and size of the organic templates are believed to influence the framework structure by stabilizing intermediate species during the nucleation. Further, the organic molecules provide an energetic stabilization to a given structure and therefore, it has a structure directing effect due to a thermodynamic effect by which the structure would minimize the energy of the inorganic-organic system, and ultimately the zeolite will be formed. Hence, the development of organic molecules that are used to direct zeolite crystallization is a major approach to novel synthesis of microporous materials.

The incorporation of organic template controls and stabilizes to some extent the pore structure of the zeolite through electrostatic interactions between the framework and the occluded organics. However, the organic templates are not as specific as anticipated since the same organic template can be used for synthesis of several zeolite phases [16]. Another recent example is the preparation of 11 different structures as B-rich, pure-Si and aluminosilicates using 16 imidazolium SDAs [17,18]. Besides, organic-template-assisted zeolites require a series of post synthesis treatments (purification, extraction or calcination) to discharge the templates occluded in the pores of the zeolites. In general, the removal of template has undesired effects on the crystalline structures such as partial or complete collapse of the pore structure and framework and partial release of the aluminium from the framework. Moreover, the production cost and the environmental regulations for chemical production are more restrictive, and therefore the combustion of organic templates becomes a much-undesired approach nowadays. Therefore a special attention on the development of recyclable SDAs has been paid $[19,20]$. One approach is based on the fragmentation and recovery of organic templates and successive use in more synthesis cycles (Fig. 3a). The other approach is based on the reuse of non-reacted SDAs after low temperature synthesis (bellow $100^{\circ} \mathrm{C}$ ), which results in significant decrease of the consumption of initial materials and mainly SDAs and ultimate decrease of pollution and product price (Fig. 3b). Another approach involves the replacements of the primary SDAs with commercially available low cost organic templates in order to prepare highly desirable zeolites [3].

During the last several years the synthesis of zeolites in fluoride media is back on the scene. The first patent describing the synthesis of MFI-type zeolite in the presence of $\mathrm{F}^{-}$mineralizer is dated from 1978 [21], while the first scientific paper was presented by

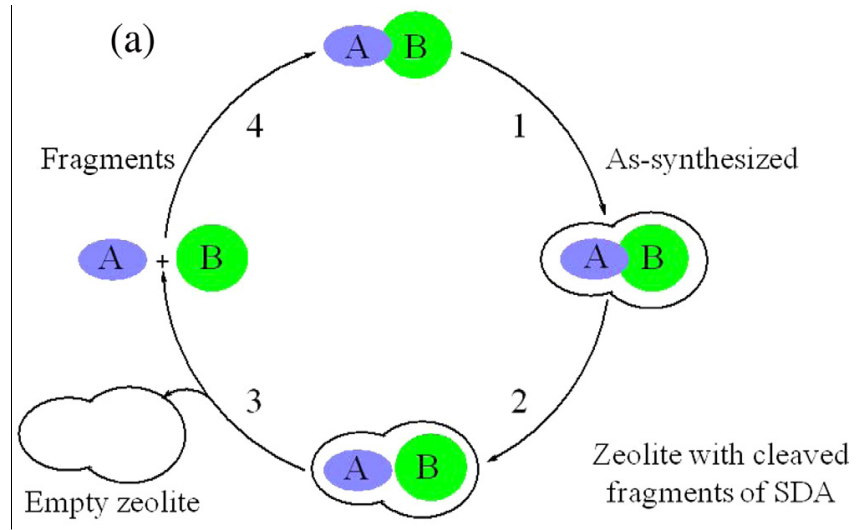

(b)

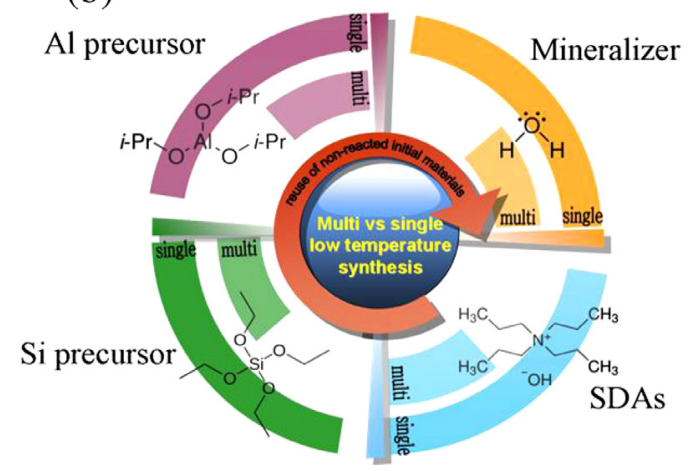

Fig. 3. Development of recyclable SDAs: (a) possibility of fragmentation and recovery, and (b) reuse of non reacted SDAs after low temperature synthesis.

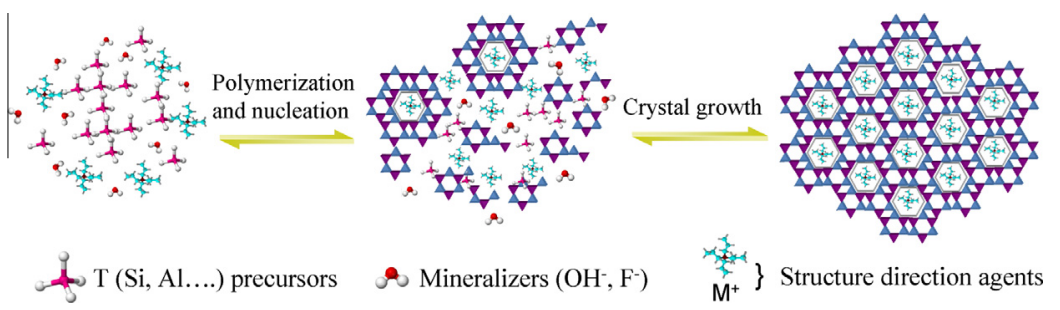

Fig. 2. General scheme of zeolites synthesis. 
Guth at the 8th IZC in Tokyo [22]. Currently, the syntheses of great number of large and extra-large pore zeolites in the presence of heteroatoms such as Ge, B and Ga are carried out in fluoride media [23]. On one side, the fluoride ions compensate the positively charged SDAs, and on the other side it has been found to stabilize small cages such as D4R, which are the secondary building units and the base for the formation of extra-large zeolites. Moreover, the synthesis of the zeolites using $\mathrm{F}^{-}$can be carried out in close to neutral $\mathrm{pH}$ media, and this will allow (i) the incorporation of heteroatoms insoluble at high $\mathrm{pH}$, and (ii) the use of SDAs non stable in highly basic media. The fluoride ions also favor the formation of defect-free high-silica zeolites and allow their processing in highly concentrated gel systems.

Lately, the seed-assisted methods have been largely explored for the preparation of various high-silica zeolites with wide industrial application $[24,25]$. Seed crystals are often present in the reaction mixtures if the reactors are not cleaned properly, however in many cases they are added on purpose. The seed-assisted methods have opened up a new avenue for the synthesis of various zeolites with wide industrial application and lead to a broadening of the types of zeolites with high crystalline yield and long-term stability. As a summary, the main advantages of seed-assisted method are: (i) no organic template is used, (ii) high phase purity can be achieved, (iii) high silica zeolites can be prepared, (iv) zeolites with compositions beyond the limits imposed by the organic template can be synthesized, and (v) the process can be easy scaled up.

In addition to the chemistry of the precursor suspensions, the physical conditions including sequence of mixing of initial compounds, aging, heating type (conventional, microwave, sonication), heating time, static/rotational reactors, and cooling rates have significant effect on the entire crystallization process of zeolites (Fig. 1). Among these parameters, the heating type has a noteworthy influence on zeolite synthesis process. The microwave and sonication accelerate the nucleation through rapid and uniform heating of the initial system producing small particles with a uniform size distribution. Moreover, a substantial reduction of the synthesis time coupled with full conversion of the precursor system into zeolites is important from industrial point of view. Compared to conventional heating, the microwave (sonication)assisted hydrothermal method also provides an efficient way to synthesize various zeolite nanocrystals with high control of their particle size distribution, yield, phase purity and morphology (Fig. 4). In conventional autoclaves, the time required to heat the suspensions to a specific temperature is long, and consequently the heating is very inhomogeneous and leads to local and temporal heterogeneities during crystallization (Fig. 4b). Microwaves produce an "internal" heating of the precursor suspension resulting often in significant changes of the kinetics and selectivity of all reactions involved. The microwave synthesis also leads to high conversion of the amorphous precursor suspensions in highly crystalline zeolite, thus effecting on the yield and phase purity. The possibility for scaling of the microwave process in continuous mode is visible and already applied for preparation of metal organic framework type materials (MOF).

Another approach for preparation of new two-dimensional zeolites is based on post synthesis treatment of already crystalline molecular sieves. The first report of on the preparation FER-type two-dimensional zeolite was presented by Corma [26]. Currently numerous approaches are under development and the most applied involve (i) exfoliation of zeolites (delamination), (ii) expanding layers by adding pillars of thermally stable inorganic components, (iii) generating of 3D structure with pores larger than parent zeolite, and (iv) full delamination of 2D zeolite in single layers randomly arranged resulting in hierarchical structures. More details on the preparation of two-dimensional zeolites and their properties can be found in the recent review papers published by Roth and Pastore $[27,28]$.

\subsection{Views on crystallization mechanism of zeolites}

The thermodynamic analyses of systems yielding zeolites suggest that kinetic factors are of major importance for the formation of a particular zeolite. More precisely, the kinetics of nucleation is the critical step that determines the product from the zeolite synthesis. Hence, mastering of the zeolite formation to great extent means fine control of the zeolite nucleation in precursors with different chemistry and at various synthesis conditions. The early stages of formations of species are of significant importance for the properties of the crystals, such as framework types, morphology and particles sizes. Therefore a special attention to the crystallization of zeolites from water clear suspension has been paid where numerous in situ characterization approaches have been utilized. A simplified system based on templated pure silica precursor suspensions enabling the direct study of the molecular assembly process and formation of zeolite nanocrystals has been investigated in details by many groups. A recent review paper has summarized the main reports on the formation of zeolites from clear suspensions [4,29]. In general in pure silica precursor systems, the initial formation process involves the hydrolysis of alkoxysilanes followed by condensation-polymerization, and ultimately formation of discrete particles smaller than five nanometers. The proposed mechanisms of aggregation of such particles leading to formation of zeolite nanocrystals are (i) transformation of an amorphous into crystalline phase, (ii) assembly of building blocks possessing structural characteristics of the final material via interaction with templates, (iii) monomer addition for formation of the solid material, and (iv) combination of the three main mechanisms. In many cases it was clearly shown that amorphous solid particle with structural elements are present in the precursor mixtures. Then rearrangement in the amorphous solid particles (a)

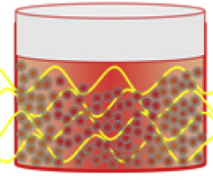

Advantages of microwave synthesis approach:

1. Efficient control of size, yield, phase purity, morphology

2. Accelerates the nucleation via rapid/uniform heating

3. High conversion of amorphous precursors into zeolites

4. Possibility for scale up in a continuous mode (c)

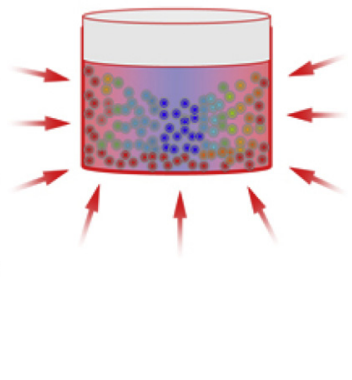

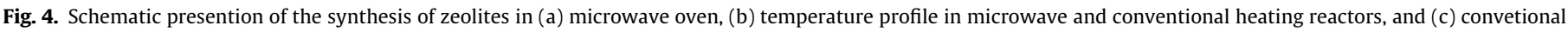
oven. 

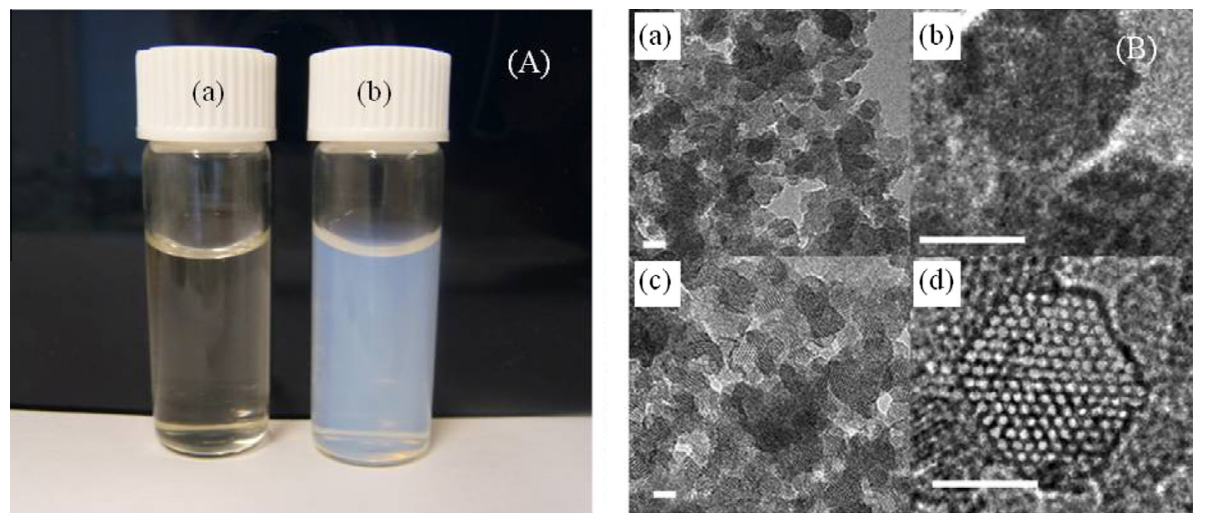

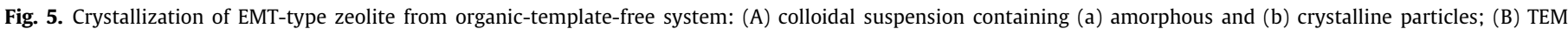
pictures of (a,b) amorphous and (c,d) crystalline particles; $M=10 \mathrm{~nm}$.

leading to the formation of the first ordered regions with zeolite structure and total transformation into fully crystalline particles occurred under certain physical conditions.

The formation of zeolite nanocrystals in both the organic-templated and organic-template-free precursor suspensions has been studied [12-15]. The ultimate size and shape of the particles are almost constant during the entire process of hydrothermal treatment, and this is exemplified in Fig. 5. The birth and growth of the LTA, MFI, FAU and EMT-type zeolites synthesized from clear precursor suspensions with and without organic templates were directly observed by HRTEM and confirmed with X-ray diffraction and dynamic light scattering approaches. The crystallization process in these systems proceeds at the expense of the amorphous solid and further treatment results in the complete transformation into fully crystalline samples. Moreover, low temperature synthesis techniques for discrete zeolite nanocrystals from organic-free precursor systems are highly desired. Such techniques offer reduced cost and hazardous wastes, save energy and allow for fine-tuning of the properties of the materials. In particular, the nucleation at low, including ambient temperature is an appropriate approach to control zeolite nucleation and favor the formation of a desired zeolite. The "soft" chemistry approach is used to control the formation of a less stable phase and avoid the formation of competing zeolite materials.

\section{Nanosized zeolites}

The discovery of new families of porous materials is offering new opportunities; however, the modification and fine-tuning of the properties of porous solids have always been in the focus of academic and applied research. The high interest in the nanosized porous materials at the beginning of the new millennium is a part of the revolution in the nanotechnology. It is known that the driving force for many processes is the local environment of atoms exposed at solid surfaces compared to that in the bulk [30]. Therefore in order to increase the number of surface atoms in the solids, two main approaches are applied: (a) decrease the size of dense particles or (b) create an open pore network within the bulk solid. The combination of these two approaches leads to the formation of nanosized zeolites with accessible and uniform pores.

The approaches applied toward nanosized molecular sieves are (i) synthesis from clear precursor suspensions in the presence of organic template, (ii) low temperature synthesis from highly alkaline organic-template-free hydrogels, and (iii) alternative methods including ionothermal, seed-induced and confined space synthesis [29-33]. In general the subdivision of any material into fine particles leads to immense specific surface areas that affect their properties. The reduction of the size of zeolite crystals to the range of several unit cells provides materials with completely new properties. Decreasing the zeolite crystal size or changing their morphology should be effective in improving the diffusion properties and in utilizing the entire pores in the considered applications. Many zeolites as aluminosilicates, pure silicates and aluminophosphates have been successfully synthesized [30-33].

The crystallization mechanism of nanosized zeolites has been followed with numerous in-situ and ex-situ characterization techniques. More interestingly, it is found that the nucleation and crystal growth processes of the nanosized zeolites in the suspensions with organic- or inorganic-structural directing agents proceed in the same manner (Fig. 6). As can be seen, both water clear precursor suspensions consist of distinct solid and liquid parts [12,14]. The amorphous particles have large specific surface area and small size, which is favoring fast species exchange between the solid and liquid parts. With further development of the crystallization process, each amorphous particle is transformed into singe crystalline zeolite. The only one obvious difference between the two systems is the type of the structural directing agents: organic (tetraalkylammounium cations, $\mathrm{TAA}^{+}$) used for LTA-type zeolite versus inorganic (alkali metal cations, $\mathrm{M}^{+}$) used for EMT-type zeolite.

Once zeolite crystals with a desired size and shape are prepared they need to be maintained non-agglomerated and stable in suspensions. The zeolite nanocrytals are also considered as hierarchical zeolites since they consist of micro- and meso-pores, which are due to the perfect packing of the individual crystallites (textural porosity). In order to create additional porosity in the zeolites, post synthesis modification including de-silication, de-alumination or steaming is usually applied to micron-sized crystals. These methods have been devoted to the preparation of zeolites with enhanced accessibility of the reactant molecules in order to achieve higher product yield/selectivity and to meet the undergoing industrial needs described recently [34]. While in the case of nanosized zeolites, the presence of mesopores in addition to the micropores is evident without any post synthesis treatments (Fig. 7). The nanosized zeolites comprise high micro- and meso-porosity. Even regular macropores $(>50 \mathrm{~nm})$ can be formed by close packing of nanocrystals with uniform size and shape resulting in hierarchical materials.

The outstanding properties of zeolites with reduced particle sizes are summarized in Fig. 8. The large and reactive external surface of the zeolite nanocrystals is critical for the design of different morphological constructions, where any further processing does not affect the intrinsic properties of the nanocrystals. The adjustable surface properties and fine-tuning of bulk properties is a base for their advanced applications. The nanosized zeolites are 

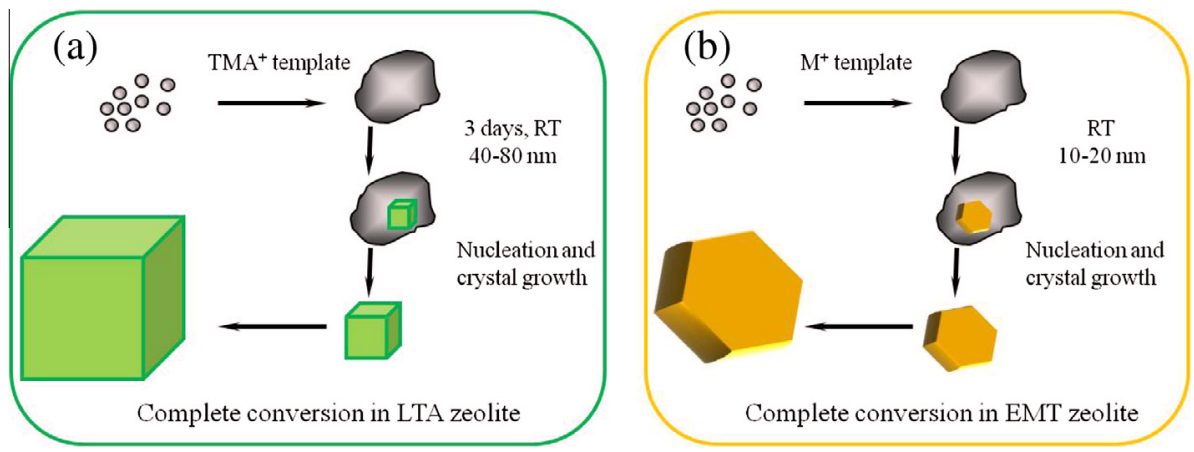

Fig. 6. Schematic presentation of the crystal growth of (a) nanosized LTA-type zeolite in organic-templated (tetramethylammonium hydroxide, TMA.OH) precursor suspension and (b) nanosized EMT-type zeolite in alkali metal-templated (sodium hydroxide, $\mathrm{NaOH}$ ) precursor suspension.

(a)

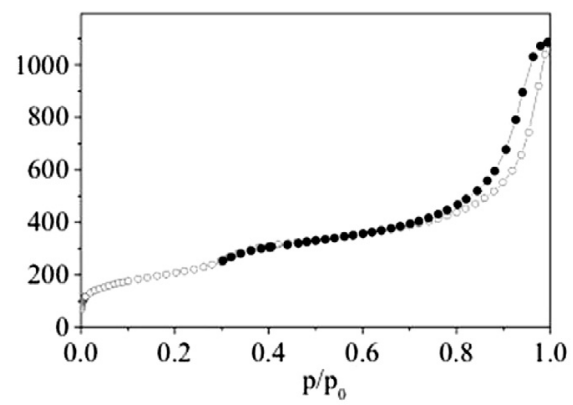

(b)

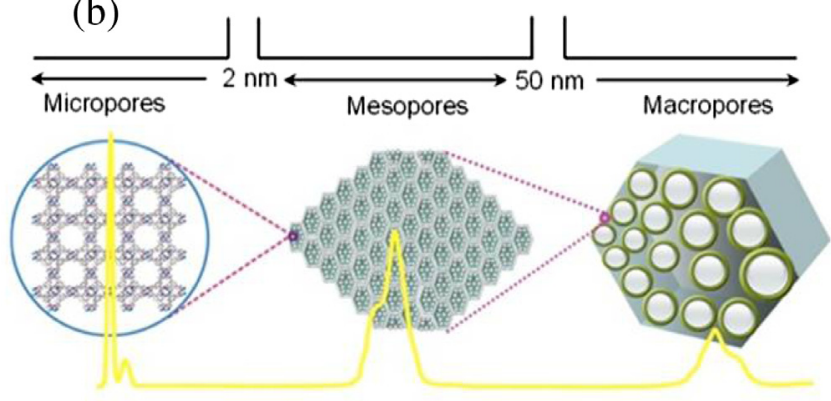

Fig. 7. (a) $\mathrm{N}_{2}$ sorption isotherm of nanosized zeolite comprising high micro- and meso-porosity, and macroporosity $(>50 \mathrm{~nm})$ formed by close packing of the nanocrystals with uniform size and shape, and (b) schematic representation of the micro-, meso- and macro-pores of zeolites.

characterized by extremely high accessibility and fast diffusion (in/ out) of various organic and inorganic guests within the zeolite pore systems.

The properties of nanozeolites allow for their integration in nanotechnological processes. Three original applications of nanozeolites in photovoltaic, holographic sensors and medicine will be illustrated in the next sections. These applications are stimulated by the new appearance and possibility of integration of the nanozeolites in stable colloidal suspensions, thin ordered films and composites. Moreover, the nanosized zeolites have shown that they are non-toxic (see Section 3).

\section{Novel applications}

\subsection{Zeolites for photovoltaic applications}

Recently, strong attention has been directed towards the use of porous nanoparticles in the fabrication of optical devices and specifically in photovoltaic solar cells due to their rigid structure, high thermal stability and availability in different morphologies in addition to their highly organized channels and cavities. The presence of charge compensating cations that are non-covalently bonded to the zeolite surface or placed within the channels offers the possibility of replacing them with different fluorescent molecules or metallic nanoparticles/clusters with special optical properties. In fact, the use of zeolite crystals in photovoltaics has not been described so far in the literature; however, progressive improvements are being achieved in the type of materials needed for such applications (Fig. 9).

Calzaferri and co-workers have reported the first example of organic dyes encapsulated in the channels of cylindrical nanocrystalline zeolite L forming host-guest composites for light harvesting and energy transfer presenting the original model of zeolite-based photovoltaic solar cell [35]. This system was built up in three stages: (i) the organic dyes were first diffused into the channels of zeolites to prevent their aggregation that leads to quenching of fluorescence; these dyes were used for light harvesting and transport of energy from the center to both ends of the cylinder or from the ends to the center following systematic arrangement of the dyes according to their donor/acceptor properties;

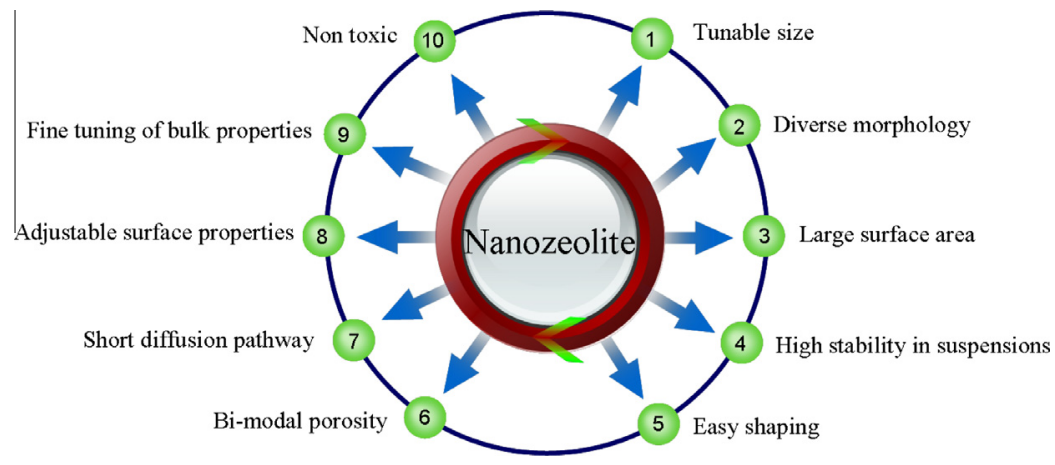

Fig. 8. Properties of nanosized zeolites. 


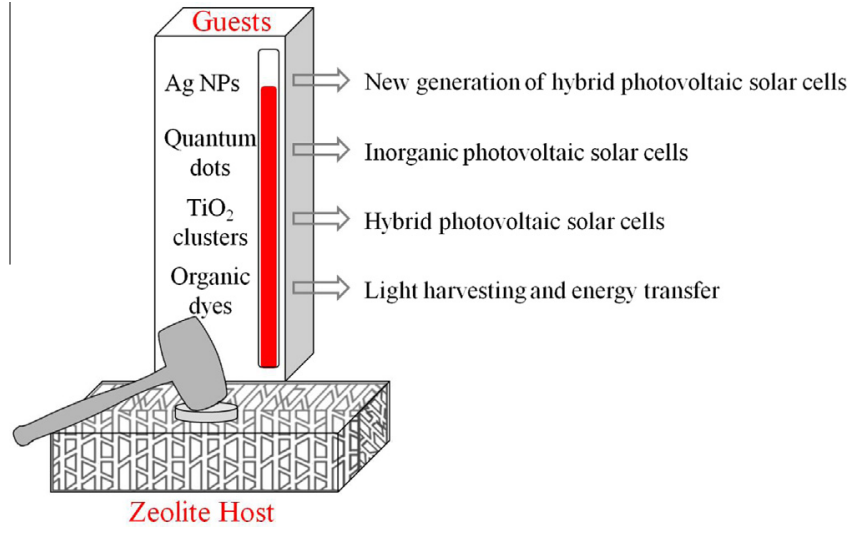

Fig. 9. Evolution of materials based on zeolites for photovoltaic applications.

(ii) fluorescent stopcocks were introduced on both sides of the zeolite channels to perform a dual task, they prevent the small organic dyes from going out of the zeolite channels, and additionally they trap or inject electronic excitation energy due to their donor or acceptor properties, (iii) the coupling to an external device through the stopcock molecules was the last stage of organization. The devices were prepared by introducing mono or multi-layers of zeolite crystals perpendicularly to a quartz film that separated them from a thin semiconductor layer of few hundreds of nanometers. The working process can be summarized by absorption of light by the dye-zeolite composite and energy funneling to the semi conductor that is responsible for the electron-hole formation.

After this first example, new photovoltaic solar cell based on zeolite $\mathrm{Y}$ crystals encapsulating discrete clusters of $\mathrm{TiO}_{2}$ (several nanometers in size) with a low loading of $4.8 \%$ within their voids is developed [36]. The zeolite- $\mathrm{TiO}_{2}$ system was modified by adsorption of organic acids or by nitrogen doping. The fabricated cells showed interesting photovoltaic activity with the N-doped zeolite- $\mathrm{TiO}_{2}$ having a voltage open circuit $\left(\mathrm{V}_{\mathrm{OC}}\right)$ of $270 \mathrm{mV}$, current closed circuit $\left(\mathrm{I}_{\mathrm{SC}}\right)$ of $5.8 \mu \mathrm{A}$ and a fill factor $(\mathrm{FF})$ of $0.4 \mathrm{~A}$. These values are 20 times less compared to the pure $\mathrm{TiO}_{2}$ based solar cells. However, considering the low loading of titanium dioxide within the zeolite (4.8\%) this photovoltaic activity is relatively strong. This system exemplifies the encapsulation of $\mathrm{TiO}_{2}$ within zeolite channels for photovoltaics. Nevertheless, it is limited by the low efficiency and requires organic modification or doping without which its efficiency would decrease sharply to $10 \%$.

To improve the efficiency, different types of zeolites such as Ti/ Beta, TS-1 and ETS-10 with different titanium content (1-7\%) uniformly dispersed within the framework and modified with N3 (ruthenium polypyridyl) dye for application in dye-sensitized solar cells (DSSCs) were explored [37]. These systems present interesting photoresponses which are higher than those previously reported, the response is directly proportional to the amount of titanium used reaching $\mathrm{V}_{\mathrm{OC}}$ of $560 \mathrm{mV}$ for Ti/Beta, which is in the range of pure titan DSCCs $\left(\mathrm{V}_{\mathrm{OC}}=770 \mathrm{mV}\right)$. In addition, it was found that the photovoltaic activity was mainly due to the titanium particles located on the external surface of zeolite with a minor contribution from those located in the channels, thus, explaining the low efficiency realized in the previous report where all the titanium clusters were inside the zeolite channels.

Recently, Yoon and co-workers reported new photovoltaic solar cells based on quantum dots ( QDs $=\mathrm{CdS}$ and PdS) encapsulated in the voids of zeolite $Y$ with interesting properties [38]. Different amounts of QDs were introduced into the zeolite occupying a maximum of $22 \%$ of the channel spaces that ensure the isolation among the quantum dots. Measurements performed on CdS-zeolite based devices showed a strong photovoltaic activity that increased with the increase of $\mathrm{CdS}$ content up to $\mathrm{V}_{\mathrm{OC}}$ of $423 \mathrm{mV}$ and $\mathrm{I}_{\mathrm{SC}}$ of $0.3 \mathrm{~mA}$. Meanwhile, the activity of PdS-zolite based devices was almost negligible due to electron-hole recombination caused by small energy difference between valance band and conduction band. Interestingly, the use of PdS-containing zeolite as counter electrode in CdS-based cell strongly enhanced the cell efficiency; $\mathrm{I}_{\mathrm{SC}}$ was increased three times up to $0.98 \mathrm{~mA}$ and $\mathrm{V}_{\mathrm{OC}}$ to $978 \mathrm{mV}$. This new type of solar cells is of special interest since it allows the incorporation of more than one type of quantum dots into the cell to achieve the best performance. However, a major problem of this strategy is the low loading of quantum dots that can be encapsulated (22\%), above which a destruction of zeolite framework can be induced.

The focus of our research is on the preparation of silver nanoparticles, which present strong plasmonic property, and this makes them attractive candidates for optical applications. This property depends strongly on the particle size, morphology and density of Ag nanoparticles. Besides, a systematic modification of these parameters allows tuning of the plasmonic response over the whole visible spectrum. Therefore the use of silver nanoparticles supported on zeolite crystals is considered for enhancing the efficiency of hybrid photovoltaic solar cells. In fact, the Ag nanoparticles are expected to play a second role in photovoltaic solar cells, in addition to their plasmonic properties. Indeed the Ag nanoparticles will induce light scattering thus extending the light path and hence increasing the number of photons entering the cell. Furthermore, the application of $\mathrm{Ag}$ nanoparticles will allow the fabrication of very thin photovoltaic solar cells (few hundreds of micrometers), which overcomes the problem of hole-electron recombination or loss of excitation from which classical solar cells suffer.

The Ag nanoparticles can be deposited selectively in the channels or on the surface of zeolite nanocrystals with one- and three-dimensional pore structures (Fig. 10). The zeolite crystals with variable morphology including plates, hexagons, spheres, and cubes can be synthesized using organic-free (EMT, LTL) or organic-templated (LTA, MFI, BEA) synthesis approaches [12-15,3133]. The silver is introduced via impregnation on the surface of templated zeolites, while in the absence of organic templates, the silver is introduced by ion exchange in the channels by replacing the sodium cations. Subsequently silver is reduced from $\mathrm{Ag}^{+}$to $\mathrm{Ag}^{0}$ by physical (UV or microwave treatment) or chemical approaches.

The reduction of $\mathrm{Ag}^{+}$is also achieved under microwave treatment of suspensions using excess of triethylamine reducing agent. The silver cations on the surface of zeolite nanoparticles were fully reduced after irradiating the zeolite suspension at $100{ }^{\circ} \mathrm{C}$ for $20 \mathrm{~min}$. The plasmon band at $405 \mathrm{~nm}$ (not shown here) gives rise to the same species obtained after the chemical treatment. Besides, the formation of Ag NPs under UV irradiation in the presence of reducing agent (2-hydroxy-2-methylpropiophenone) was investigated, and the results were similar to the one reported above. The presence of Ag NPs on the surface and in the channels (Fig. 11) of zeolites was confirmed by TEM. The surface of the LTA type zeolite nanocrystals is fully covered with Ag NPs, moreover the Ag NPs are equally distributed (space of $5 \mathrm{~nm}$ between individual Ag NPs). Besides, the Ag NPs predominantly formed in the cannels of BEA-type zeolites are clearly observed in Fig. 11b. The fringes corresponding to the BEA-type zeolites confirm the stability of the crystals under introduction of Ag NPs.

Different zeolite nanocrystals namely MFI, BEA, EMT and FAU were used as solid supports for the preparation of Ag NPs with spherical, hexagonal and octahedral morphologies, respectively. The results obtained in each case together with their performance in photovoltaic applications will be described elsewhere. 


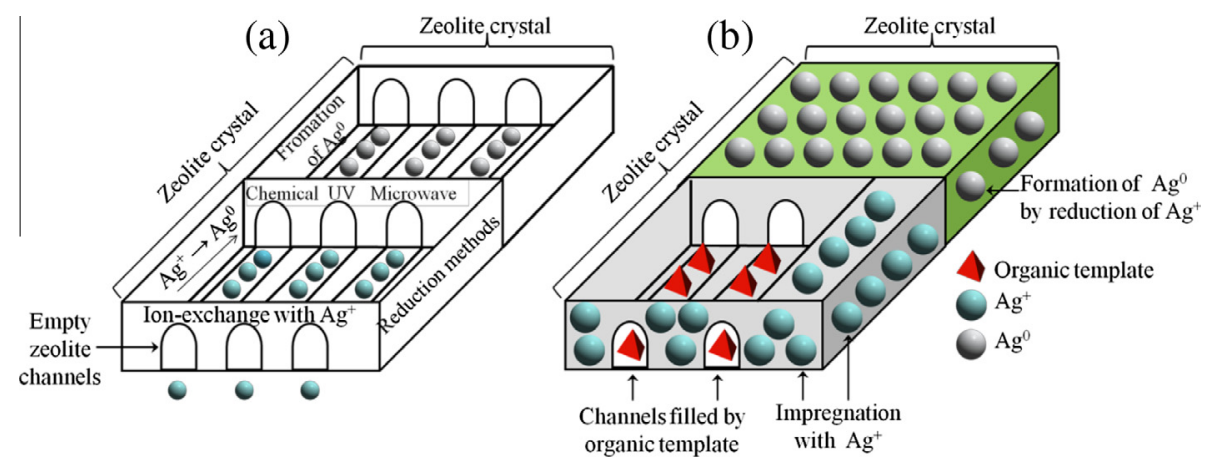

Fig. 10. Strategy for preparation of Ag nanoparticles: (a) in the channels and (b) at the surface of zeolites.

(A)

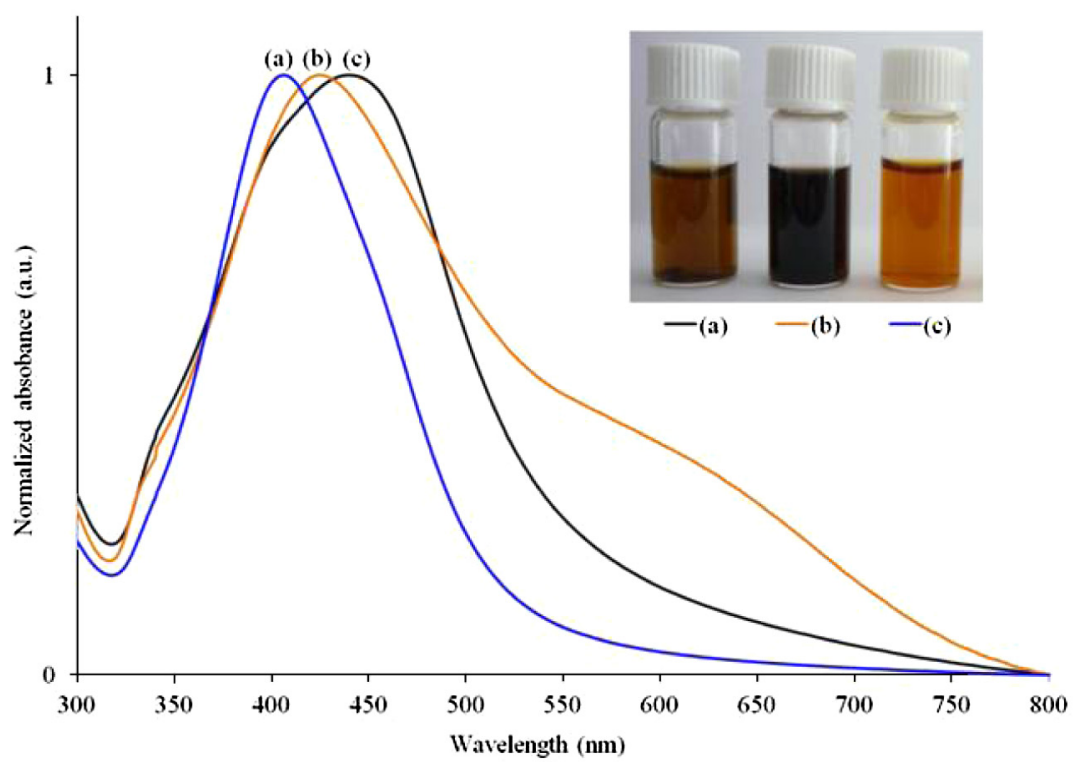

(B)
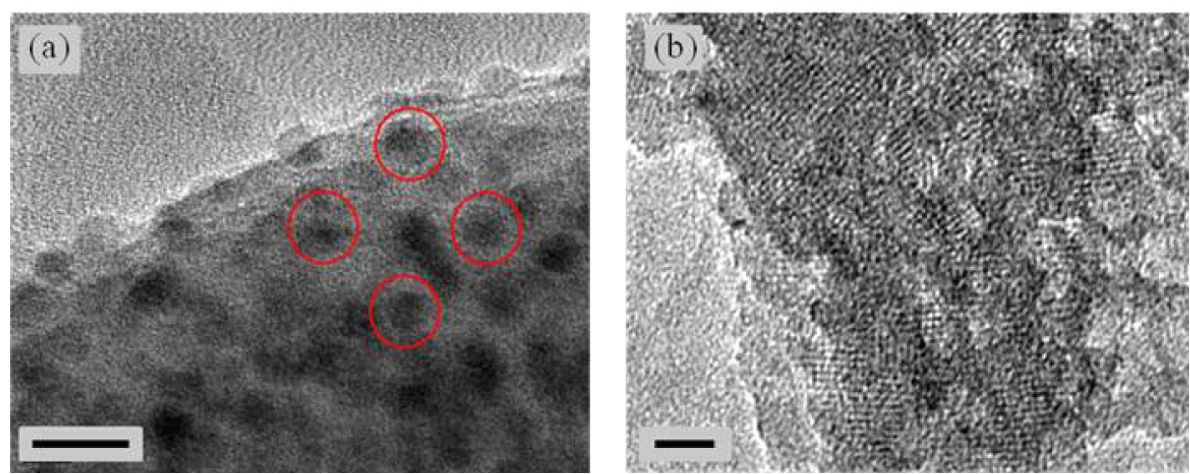

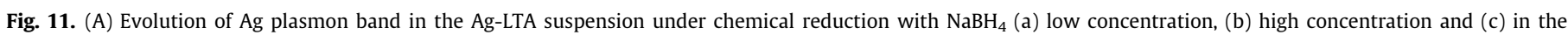

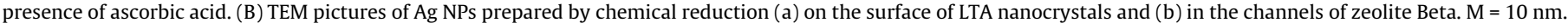

\subsection{Zeolite for antimicrobial and medical applications}

In this section the application of silver containing zeolites in antimicrobial and medical applications will be outlined. While micron-sized zeolites are considered as non-toxic and environmentally benign, no significant attention to the impact of nanosized zeolites on health and safety issues have been paid. In the recent years, several toxicological studies [39-42] proved that zeolites are non-toxic. Besides, incorporation of silver in zeolites has shown to improve their stability, and hence allows good performance required for optical and biomedical applications [43-46]. One of the important applications of silver containing zeolite crystals is as antimicrobial agent. The mechanism of zeolite's antimicrobial effect is explained as follows: when moisture or liquid film gets in contact with the zeolite which is exchanged by silver, the silver ions are released to the bacteria by forming chelate complexes 
with the DNA and block the transport processes in the cell [47]. By increasing the $\mathrm{Ag}$ loading in zeolites an increased antimicrobial activity was observed [48-50]. Inoue and co-workers reported on the antibacterial activity of silver-loaded FAU zeolite against Escherichia coli [51], thus showing an increase in bacterial susceptibility in the case of rifampicin. Additionally, patterned-zeolite films consisting of FAU zeolite crystals were also found to be efficient towards eradication of E. coli. [52]. The silver-loaded zeolite (Ag concentration of $0.15-1.0 \mathrm{~g} / \mathrm{L}$ ) had antimicrobial action on E. coli, Staphylococcus aureus and Pseudomonas aeruginosa within $1 \mathrm{~h}$ [53].

Substantial work has been carried out to explore the potential of mesoporous silica for drug release application, while relatively fewer studies have been reported on zeolites. Controlled drug delivery requires the optimal release of the drug in efficient amounts while minimizing the side effects that can occur depending on the dosage forms. The nanosized zeolites possess both the micropores and textural mesopores that are potentially large enough to accommodate a wide-range of different drug molecules, such as sulfonamide antibiotics, ibuprofen, doxorubicin, mitoxantrone, aspirin and 5-Fluorouracil (5-FU) [54-59]. Compared to mesoporous materials, the zeolites have shown better loading of drugs. Moreover, ibuprofen immobilized in the FAU zeolite showed better release behaviors than those observed for the MCM-41 type mesoporous material. Selective absorption and release can be realized by choosing an appropriate type of zeolites. Thus zeolites appear to be ideally suited for both enhancing the dissolution and controlling the release of drug molecules. S. Larsen and co-workers have investigated the loading and release of Aspirin [58] and 5-FU [59] in three zeolite hosts with different silica to alumina ratios (zeolite $\mathrm{Y}, \mathrm{SiO}_{2} / \mathrm{Al}_{2} \mathrm{O}_{3}=5,30,60$ ). They found that the aluminum content in the zeolite plays a critical role in determining the drug loading and release profiles. Aspirin and 5-fluorouracil loadings were found to increase with increasing aluminum content in zeolite $Y$. In this release system, the aluminum has an integral role in governing the interactions between zeolite $\mathrm{Y}$ crystals and drug molecules. The zeolite with the highest aluminum content may interact with the drug molecule species by hydrogen bonding of the carbonyl oxygen atoms with the zeolite hydroxyl groups as well through coordination of the drug molecules to the aluminum atoms. The binding between $-\mathrm{C}-\mathrm{O}$ and $-\mathrm{N}-\mathrm{H}$ moieties and the $\mathrm{Al}^{3+}$ species were confirmed by studying the 5-FU and its anti-tumor activity [60]. Two stages were observed in the Ibuprofen delivery: (i) first the release is governed by a diffusion process, and (ii) second the $\mathrm{Al}$ content is determinant in drug delivery. The framework with $\mathrm{Si} / \mathrm{Al}$ ratio of 22 shows faster release and lower one was found with the Si/Al ratio of 62 . Moreover, based on the results obtained in various tumor cells and in tumor bearing animals, the zeolites have shown that they can be successfully applied as adjuvants in anticancer therapy. Anticancer drugs have been loaded into the pores of zeolite and have shown a noticeable cytotoxic effect when applied to cancer cells $[61,62]$. In these works, zeolite Y (FAU), zeolite A (LTA) [61] and zeolite Beta (BEA) [62] were used as hosts for releasing the anticancer drug. Results showed that zeolites alone reveal no toxicity to cancer cells, while, importantly, anticancer drug-zeolite led to an inhibition of cell viability up to 585-fold when compared to the non-encapsulated drug. Moreover, mitoxantrone can also be excited at a wavelength of $600-660 \mathrm{~nm}$ and emits light at $675-685 \mathrm{~nm}$, which gives the possibility to visualize the hybrid nanoparticles in biological media [57].

Based on the advantages such as small size and controlled release, zeolite modified with a targeting molecule, such as folic acid or peptide, are recognized for application in targeting treatment of cancer cells. Zeolites functionalized with molecular targeting vectors (e.g., peptides, aptamers) that enable specific high-affinity binding to in vivo molecular targets (such as cell surface receptors) were investigated. In addition, these materials possess unique properties that enable radionuclides and contrast agent metals to be concentrated for applications in magnetic resonance imaging (MRI) and positron emission tomography (PET) [63-67].

De Cola and co-workers introduced some luminescent molecules into zeolites L (LTL-type structure), such as iridium (Ir) and europium (Eu) complexes and organic dyes for biology imaging [68-70]. The light responsive components in combination with the smallest zeolites ( $30 \mathrm{~nm}$ ) have been very successfully applied for the labeling, targeting and killing of antibiotic resistant bacteria [71]. The multifunctional nanomaterial used to target, label, and photo-inactivate antibiotic-resistant bacteria is schematically presented in Fig. 12. Zeolite L nanocrystal is loaded with the DXP emitter (green circles), while its surface is functionalized with a phthalocyanine derivative (red ellipsoid) and amino groups (blue circles), where the latter provide noncovalent binding of the hybrid nanomaterial to the bacterial surface. The results demonstrated that the hybrid nanomaterials efficiently produced singlet oxygen and adhered to bacterial surfaces, leading to targeting, labeling, and photoinactivation capabilities against antibiotic-resistant bacteria. These results open fascinating possibilities for the multifunctional biomaterial based on zeolite.

The goal of our study is to introduce noble metals $(\mathrm{Au}, \mathrm{Ag})$ with different concentration by ion exchange in ultra small zeolites, and then to reduce them under microwave irradiation. By changing the parameters of microwave treatment, amount of noble cations in the zeolites and reducing agent, the size and the shape of the metal nanoparticles are controlled. The nanosized zeolites with high accessibility and high external surface area, free of organic template are applied as solid model for the preparation of the silver and gold. The possibility to stabilized the zeolite nanoparticles containing noble metals in liquid media with time will be explored for further antimicrobial and medical applications. The silver (gold) nanoparticles contain several domains and the surface plasmon resonance band can be tuned from visible to near infrared region due to their size and shape. The antimicrobial effect of Ag NPs stabilized in EMT-type zeolites is currently under study and will be presented elsewhere.

\subsection{Holographic sensors based on zeolites}

Another application of zeolite nanocrystals is the fabrication of holographic sensors. A hologram recorded in a material capable of absorbing a specific substance is utilized in this application. The absorption of the analyte leads to a change of diffraction efficiency and/or spectral characteristics of the hologram. The holographic sensors are fabricated by exposing a suitable photosensitive material to the optical interference pattern produced by two coherent spatially overlapping laser beams. The material records, the variation in light intensity as a variation in refractive index, absorption or thickness, and a hologram is produced. The main advantages of holographic sensors are: (i) the response can be detected by an electronic device or can be detected visually, and in the second case there is no need of expensive instrumentation for sensor interrogation; (ii) their low cost facilitates the design of disposable sensors; (iii) there is a possibility for miniaturisation and holographic multiplexing of more than one sensor in a single device; (iv) the sensor holograms are normally recorded in plastic materials and thus they are light weight; and (v) with the right choice of materials, the sensors can be mass produced.

The principle of operation of a holographic sensor can be described as follow. The holographic sensor consists of a hologram that is disposed throughout a support medium, which is sensitive to the analyte. The process of detection involves a change in the optical characteristics of the hologram caused by the interaction of the analyte with the support medium. The main effort in the 


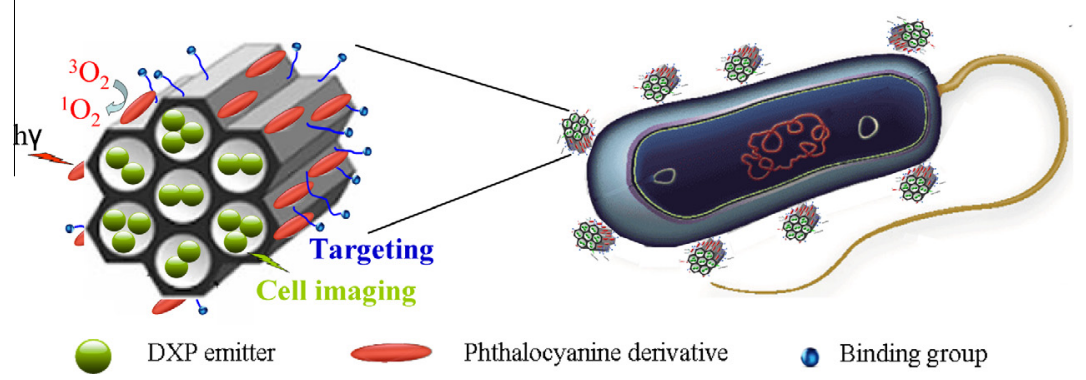

Fig. 12. Scheme of the multifunctional porous material used to target, label, and photoinactivate antibiotic-resistant bacteria.

development of holographic sensors for visual detection has been focused on reflection holographic sensors [72-76] and on optimization of the support medium to be analyte specific. The principle of operation of these holographic sensors [72-76] relies mainly on swelling/shrinking of the hologram support medium as a result of the exposure to the analyte and this leads to a visually observable change of the color of the light reflected by the hologram. Other mechanisms such as changes of the average refractive index and of the refractive index modulation are also possible. Their use in the design of sensors based on transmission holograms has been demonstrated in [77].

\subsubsection{Holographic sensors recorded in zeolite-doped photopolymers}

The use of zeolite doped photopolymers for the design of holographic sensors has been first proposed in [78]. Two different types of holographic sensors recorded in zeolite doped photopolymers have been described [78]. In both types of sensors the zeolite nanodopant is sensitive to a specific analyte. The main difference between the two sensors is that operation of the first one depends on the spatial redistribution of the analyte-sensitive nanodopants while the second requires the presence of analyte-sensitive nanodopants, but does not require their spatial redistribution. The first type of sensor can be designed to operate in transmission or reflection mode, while the second requires operation in reflection mode. Examples of sensors based on transmission holograms have been recently reported $[79,80]$. Transmission holograms recorded in zeolite Beta doped photopolymer have been used for the fabrication of holographic sensors. It has been demonstrated that the addition of $5 \mathrm{wt} . \%$ zeolite Beta to the polymer layers yields to an increase of the transmission grating sensitivity towards toluene in comparison to the undoped photopolymer [79]. The optical properties of AEI-doped photopolymer layers combined with the redistribution of the AEI nanoparticles during holographic recording have been exploited for fabrication of an irreversible humidity sensor based on a transmission holographic grating. It has been demonstrated that the diffraction efficiency of the sensor changes permanently after exposure to high humidity [80].

\subsubsection{Holographic sensor based on transmission holographic grating}

The simplest form of a hologram is the one recorded with two plane waves. The hologram in this case is a holographic grating. The fabrication of a holographic sensor based on transmission holographic grating recorded in a nanozeolite-doped photopolymer is shown in Fig. 13. The first step is the recording of the holographic grating (Fig. 13a) when the zeolite doped photopolymer layer is exposed to two interfering beams of light. During this process a redistribution of the zeolite nanoparticles takes place (Fig. 13b). The fringe spacing and the thickness of the layer have to be chosen thus that a volume transmission hologram is recorded. This provides the existence of only one order of diffraction, which intensity can be monitored. The relation between the
Before holographic recording the particles are homogeneously distributed in the photopolymer layer

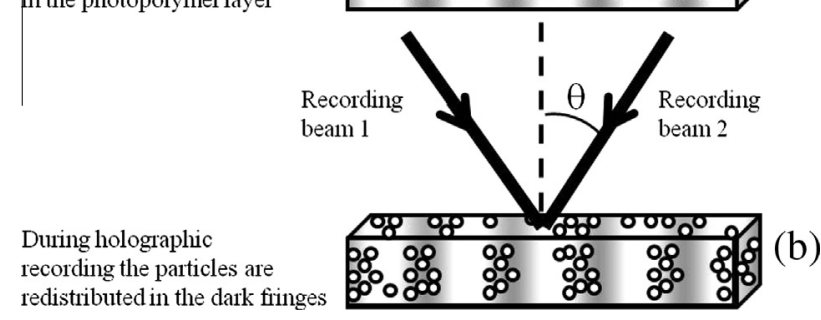

Fig. 13. Fabrication of holographic sensor based on transmission holographic grating (a) recording of the holographic sensor by illumination of zeolite doped photopolymer with two interfering laser beams and (b) redistribution of the zeolite nanoparticles in the dark fringe areas as a result of the holographic recording.

refractive index modulation and the diffraction efficiency of a thick holographic grating is given by:

$\eta=\sin ^{2}\left(\frac{\pi n_{1} d}{\lambda \cos \theta}\right)$

where $n_{1}$ is the refractive index modulation, $d$-thickness of the holographic grating, $\lambda$-wavelength of light at which the diffraction efficiency is measured, $\theta$-Bragg angle. The refractive index modulation $n_{1}$ is determined by the spatially modulated change in density and change of refractivity of the monomer molecules due to photopolymerisation and by the redistribution of the zeolite nanodopants. The contribution of the zeolite nanodopants $n_{1}^{n}$ to the refractive index modulation $n_{1}$ is given by:

$n_{1}^{n}=f_{\text {nanodopants }}\left(n_{\text {nanodopants }}-n_{\text {host }}\right)$,

where $f_{\text {nanodopants }}$ is the volume fraction of nanoparticles in the nanoparticle rich region, $n_{\text {nanodopants }}$ is the refractive index of the nanodopants and $n_{\text {host }}$ is the refractive index of the host organic matrix. As it can be seen from (2) the contribution of the zeolite nanoparticles $n_{1}^{n}$ can change due to a change of the $n_{\text {nanodopants. Such }}$ change of the refractive index of the zeolite nanoparticles is expected when an appropriate analyte is adsorbed or absorbed by the zeolite. The result of this process is a change of the diffraction efficiency of the holographic grating. Special attention must be given to the properties of the nanoparticle-doped photopolymer in order to ensure that a spatial redistribution of the nanodopant takes place as result of the recording process. The redistribution of zeolite nanoparticles has been previously confirmed by Raman spectroscopy [59-61]. When illuminated at the appropriate angle by one beam the hologram produces a second diffracted beam. The initial intensity of the diffracted beam depends on the refractive index modulation $n_{1}$ introduced during the recording (Fig. 14). If the nanoparticles are redistributed in the dark fringe areas, as it has been observed for MFI, BEA and AEI doped photopolymers 


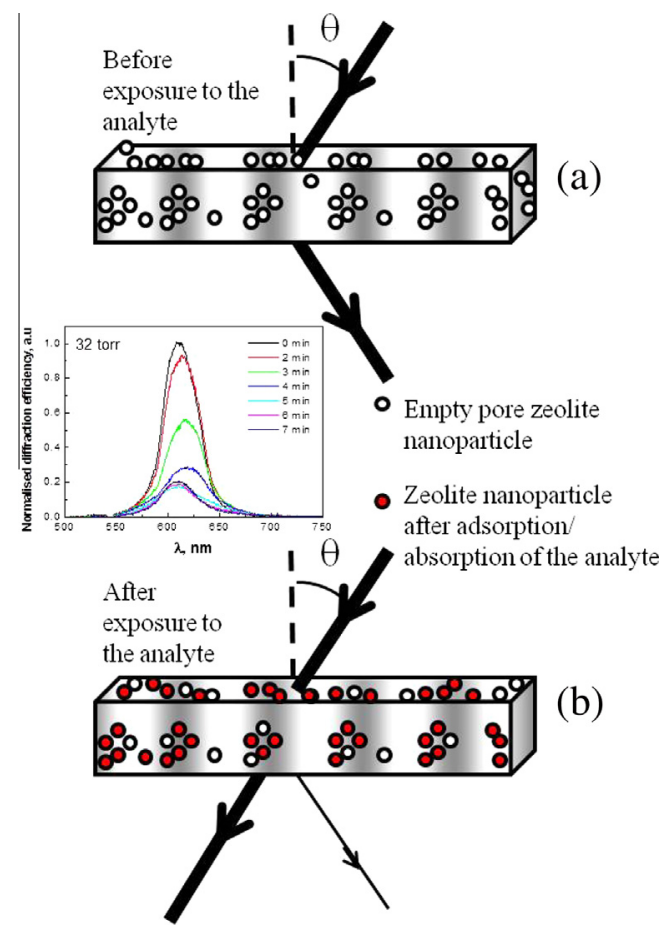

Fig. 14. Probing of the holographic sensor before (a) and after (b) exposure to the analyte. Insert: diffraction efficiency of MFI doped holographic sensor exposed to isopropanol.

[79-81], exposure of the grating to the analyte will lead to a decrease of the diffracted beam intensity.

The photopolymer layers doped with MFI zeolite nanoparticles were also prepared, and transmission holographic gratings were recorded. Investigation of the porosity and the refractive index of the nanocomposite material revealed that the pores of the zeolite nanoparticles remain empty after their addition to the photopolymer. The hologram samples were mounted in a gas chamber and exposed to different vapours: methanol, ethanol, butanol, isopropanol, cyclohexene, tert-butylcyanide, 2-methylrpopanol, methyl butanol, cyclohexanol and isobutyraldehyde. The example response of the sensor, exposed to isopropanol vapour is shown in Fig. 14 (see insert). It can be seen that the presence of isopropanol in the gas chamber leads to decrease of the diffraction efficiency of the holographic sensor. This change is reversible, since the initial diffraction efficiency was completely recovered when the vapour pressure in the chamber was reduced to 0 torr. Similar decrease in the diffraction efficiency was observed in presence of analytes characterized by the linearity of their organic chains and with a size of the analyte molecules smaller than the pore size of the MFI zeolite. No change of the diffraction efficiency was observed in the reference holographic grating recorded in undoped photopolymer layer. These observations reveal that by careful matching of the properties of analyte and zeolite nanoparticles used as dopants it is feasible to achieve selectivity of the sensors toward specific analytes.

\section{Conclusions}

A substantial progress in the preparation of new structures, hierarchical zeolites and ultra small discrete zeolite crystals has been accomplished. The main achievements have been realized by manipulating the precursor synthesis gel/suspension and the directing role of cations, types of initial silicon and aluminum precursor sources, types of organic templates, by variation of synthesis conditions like temperature, pressure, time, and heating methods including microwave and sonication. A special attention on the chemical composition (water content, alkalinity, additives, templates) has been paid in order to keep the high crystalline yield but also to obtain pure zeolite phase with discrete particles. Although the zeolite synthesis is regarded to be a batch process under conventional heating, the continuous crystallization under microwave and sonication treatment is becoming interesting for further processing. The goal is to increase the efficiency of the synthesis procedure by increasing the zeolite yield, decreasing the crystallization time, energy and time saving by diminishing nucleation process.

With the further development of zeolite chemistry, not only many new framework structures are synthesized, but also new technologies are developed allowing for a greater control of crystal size, morphology, acidity, and porosity. The decrease of zeolite crystal size to nanoscale not only brings a large external surface area, but also provides attractive materials with uniform and adjustable bulk/surface properties. The zeolite nanoparticles can be easily modified and different functionalities can be introduced.

The improvements in zeolite synthesis broaden their applications in the fields of green chemicals, medicine, nanotechnology, pharmaceutical, and food industry. Zeolite nanocrystals offer promises in the above applications due to their highly tuneable size- and shape-dependent chemical and physical properties. Their unique surface chemistry, high surface area and large pore volume are important and show high potential for designing of new materials for photovoltaic, selective sensors, memebranes and medical applications.

\section{Acknowledgements}

The financial support from MEET INTEREG EC and the LowerNormandy Region (SOLAIRE project) are acknowledged.

\section{References}

[1] J. Čejka, A. Corma, S. Zones, Zeolites and Catalysis: Synthesis, Reactions and Applications, 1st ed., Wiley-VCH, New York, 2010.

[2] J.-P. Gilson, O. Marie, S. Mintova, V. Valtchev, "Emerging Applications of Zeolites" in Zeolites and Ordered Porous Solids, 3rd FEZA School on Zeolites: Fundamentals and Applications, Editorial Universitat Politècnica de València, Valencia, 2011.

[3] G. Bellussi, A. Carati, C. Rizzo, R. Millini, Catal. Sci. Technol. 3 (2013) 833-857. [4] C.S. Cundy, P.A. Cox, Chem. Rev. 103 (2003) 663-702.

[5] R.M. Barrer, Hydrothermal Chemistry of Zeolites, Academic Press, London, 1982.

[6] R. Szostak, Molecular Sieves. Principles of Synthesis and Identification, Blakie Academic \& Professional, London-Weinheim-New York-Tokyo-MelbourneMadras, 1998.

[7] J.C. Jansen, in: H. van Bekkum, E.M. Flanigen, P.A. Jacobs, J.C. Jansen (Eds.), Introduction to Zeolite Science and Practice, Studies in Surface Science and Catalysis, vol. 137, Elsevier, Amsterdam, 2001, pp. 175-224.

[8] S.L. Burkett, M.E. Davis, Chem. Mater. 7 (1995) 920-928.

[9] W.H. Dokter, H.F. Garderen, T.P.M. Beelen, R.A. Santen, W. Bras, Angew. Chem. 34 (1995) 73-75.

[10] B.J. Schoeman, Micropor. Mater. 9 (1997) 267-271.

[11] A. Palčić, B. Subotić, V. Valtchev, J. Bronić, CrystEngComm 15 (2013) 57845791.

[12] E.-P. Ng, D. Chateigner, T. Bein, V. Valtchev, S. Mintova, Science 335 (2012) 70 73.

[13] V.P. Valtchev, K.N. Bozhilov, J. Am. Chem. Soc. 127 (2005) 16171-16177.

[14] S. Mintova, N. Olson, V. Valtchev, T. Bein, Science 283 (1999) 958-960.

[15] S. Mintova, N. Olson, T. Bein, Angew. Chem. Int. Ed. 38 (1999) 3201-3204.

[16] C. Martinez, A. Corma, Coord. Chem. Rev. 255 (2011) 1558-1580.

[17] S. Zones, Micropor. Mesopor. Mater. 144 (2011) 1-8.

[18] R.H. Archer, S.I. Zones, M.E. Davis, Micropor. Mesopor. Mater. 130 (2010) 255 265.

[19] H. Lee, S.I. Zones, M.E. Davis, Nature 425 (2003) 385-388.

[20] E.-P. Ng, L. Delmotte, S. Mintova, Green Chem. 10 (2008) 1043-1048.

[21] E. Flanigen, R.C. Patton, US Pat 4,073,865, 1978.

[22] J.L. Guth, H. Kessler, R. Wey, Proc. 8th Int. Zeolite Conf. IZC, Tokyo, 1986, p. 121

[23] J. Jiang, J. Yu, A. Corma, Angew. Chem. 49 (2010) 3120-3145.

[24] G. Majano, L. Delmotte, V. Valtchev, S. Mintova, Chem. Mater. 21 (2009) 4184 4191. 
[25] Y. Kamimura, K. Iyoki, S.P. Elangovan, K. Itabashi, A. Shimojima, T. Okubo, Micropor. Mesopor. Mater. 163 (2012) 282-290.

[26] A. Corma, V. Fornes, S.B. Pergher, Th.L.M. Maesen, J.G. Buglass, Nature 396 (1998) 353-356.

[27] W. Roth, J. Čejka, Catal. Sci. Technol. 1 (2011) 43-53.

[28] F. Solânea, O. Ramos, M.K. de Pietre, H.O. Pastore, RSC Adv. 3 (2013) 2084 2111.

[29] I.H. Lim, W. Schrader, F. Schüth, Micropor. Micropor. Mater. 166 (2013) 20-36

[30] V. Valtchev, L. Tosheva, Chem. Rev. (2013), http://dx.doi.org/10.1021/ cr300439k.

[31] S. Mintova, Chem. Commun. 68 (2003) 2032-2054.

[32] L. Tosheva, V. Valtchev, Chem. Mater. 17 (2005) 2494-2513.

[33] S. Mintova, E.-P. Ng, in: S. Kitagawa, R. Bedard (Eds.), "Zeolite Nanocrystals" in Comprehensive Inorganic Chemistry II, Elsevier, Amsterdam, 2012.

[34] K. Moller, T. Bein, Chem. Soc. Rev. 42 (2013) 3689-3707.

[35] G. Calzaferri, S. Huber, H. Maas, C. Minkowski, Angew. Chem. Int. Ed. 42 (2003) 3732-3758.

[36] P. Atienzar, S. Valencia, A. Corma, H. Garcia, ChemPhysChem 8 (2007) 11151119.

[37] M. Alvaro, E. Carbonell, P. Atienzar, H. Garcia, ChemPhysChem 7 (2006) 19962002.

[38] H.S. Kim, N.C. Jeong, K.B. Yoon, Langmuir 27 (2011) 14678-14688.

[39] S. Laurent, E.-P. Ng, C. Thirifays, L. Lakiss, G.-M. Goupil, S. Mintova, C. Burtea, E. Oveisi, C. Hébert, M. de Vries, M. Motazacker, F. Rezaee, M. Mahmoudi, Toxicol. Res. Toxicol. Res. 2 (2013) 270-279.

[40] L.C.J. Thomassen, D. Napierska, D. Dinsdale, N. Lievens, J. Jammaer, D. Lison, C.E.A. Kirschhock, P.H. Hoet, J.A. Martens, Nanotoxicology 6 (2012) 472-485.

[41] T. Kihara, Y. Zhang, Y. Hu, Q. Mao, Y. Tang, J. Miyake, J. Biosci. Bioeng. 111 (2011) 725-730.

[42] K. Bhattacharya, P. Naha, I. Naydenovad, S. Mintova, H. Byrne, Toxicol. Lett. 215 (2012) 151-160.

[43] P. Kaali, M.M. Pérez-Madrigal, E. Strömberg, R.E. Aune, Gy. Czél, S. Karlson, Express Polym. Lett. 15 (2011) 1028-1040.

[44] D. Monteiro, L. Gorup, A. Takamiya, A. Ruvollo-Filho, E. Camargo, D. Barbosa Int, J. Antimicrob. Agents 34 (2009) 103-110.

[45] J. Hrenovica, J. Milenkovicb, T. Ivankovica, N. Rajic, J. Hazard. Mater. 201-202 (2012) 260-264.

[46] A. Nagy, A. Harrison, S. Sabbani, R. Munson, P. Dutta, W. Waldman, Int. J. Nanomed. 6 (2011) 1833-1852.

[47] M. Rai, A. Yadav, A. Gade, Biotechnol. Adv. 27 (2009) 76-83.

[48] K. Kawahara, K. Tsuruda, M. Morishita, M. Uchida, Dent. Mater. 16 (2000) 452 455.

[49] L. Tosheva, A. Brockbank, B. Mihailova, J. Sutula, J. Ludwig, H. Potgieter, J. Verran, J. Mater. Chem. 22 (2012) 16897-16905.

[50] L. Ferreira, A.M. Fonseca, G. Botelho, C. Almeida- Aguiar, I.C. Neves, Micropor. Mesopor. Mater. 160 (2012) 126-132.

[51] Y. Inoue, H. Hamashima, J. Biomater. Nanobiotechnol. 3 (2012) 114-117.

[52] S. Sabbani, D. Gallego-Perez, A. Nagy, W.J. Waldman, D. Hansford, P.K. Dutta, Micropor. Mesopor. Mater. 135 (2010) 131-136.

[53] B. Kwakye-Awuah, C. Williams, M.A. Kenward, I. Radecka, J. Appl. Microbiol. 104 (2008) 1516-1524.

[54] I. Braschi, G. Gatti, G. Paul, C.E. Gessa, M. Cossi, L. Marchese, Langmuir 26 (2010) 9524-9532.
[55] I. Braschi, S. Blasioli, L. Gigli, C.E. Gessa, A. Alberti, A. Martucci, J. Hazard. Mater. 178 (2010) 218-225.

[56] M. Arruebo, R. Fernandez-Pacheco, S. Irusta, J. Arbiol, M.R. Ibarra, J. Santamaria, Nanotechnology 17 (2006) 4057-4064.

[57] S. Grund, T. Doussineau, D. Fischer, G.J. Mohr, J. Colloid Interface Sci. 365 (2012) 33-40.

[58] A. Datt, D. Fields, S.C. Larsen, J. Phys. Chem. C 116 (2012) 21382-21390.

[59] A. Datt, E.A. Burns, N.A. Dhuna, S.C. Larsen, Micropor. Mesopor. Mater. 167 (2013) 182-187.

[60] K.K. Narang, V.P. Singh, D. Bhattacharya, Polyhedron 16 (1997) 2491-2497.

[61] N. Vilaca, R. Amorim, O. Martinho, R.M. Reis, F. Baltazar, A.M. Fonseca, I.C. Neves, J. Mater. Sci. 46 (2011) 7511-7516.

[62] R. Amorim, N. Vilaça, O. Martinho, R.M. Reis, M. Sardo, J. Rocha, A.M. Fonseca, F. Baltazar, I.C. Neves, J. Phys. Chem. C 116 (2012) 25642-25650.

[63] E. Csajbok, I. Banyai, L. Elst, R. Muller, W. Zhou, J. Peters, Chem. Eur. J. 11 (2005) 4799-4807.

[64] J.A. Peters, K. Djanashvili, Eur. J. Inorg. Chem. (2012) 1961-1974.

[65] F. Lerouge, O. Melnyk, J. Durand, L. Raehm, P. Berthault, G. Huber, H. Desvaux, A. Constantinesco, P. Choquet, J. Detour, M. Sma?hi, J. Mater. Chem. 19 (2009) 379-386.

[66] Y. Cheng, Q. Huang, M. Eić, B.J. Balcom, Langmuir 21 (2005) 4376-4381.

[67] M.M. Tsotsalas, K. Kopka, G. Luppi, S. Wagner, M.P. Law, M. Schafers, L. De Cola, ACS Nano 4 (2010) 342-348.

[68] M. Tsotsalas, M. Busby, E. Gianolio, S. Aime, L. De Cola, Chem. Mater. 20 (2008) 5888-5893.

[69] M. Mauro, K.C. Schuermann, R. Pretot, A. Hafner, P. Mercandelli, A. Sironi, L. De Cola, Angew. Chem. Int. Ed. 49 (2010) 1222-1226.

[70] Z. Popovic, M. Otter, G. Calzaferri, L. De Cola, Angew. Chem. Ind. Ed. 46 (2007) 6188-6191.

[71] C. Strassert, M. Otter, R. Albuquerque, A. Höne, Y. Vida, B. Maier, L. De Cola, Angew. Chem. Int. Ed. 48 (2009) 7928-7931.

[72] F.K. Sartain, X. Yang, C.R. Lowe, Chem. Eur. J. 14 (2008) 4060-4067.

[73] D. Bhatta, G. Christie, B. Madrigal-Gonzalez, J. Blyth, C.R. Lowe, Biosens. Bioelectron. 23 (2007) 520-527.

[74] I. Naydenova, R. Jallapuram, V. Toal, S. Martin, Appl. Phys. Lett. 92 (2008) 031109-031111.

[75] I. Naydenova, J. Raghavendra, V. Toal, S. Martin, Sens. Actuators B Chem. 139 (2009) 35-38.

[76] I. Naydenova, R. Jallapuram, S. Martin, V. Toal, "Holographic Humidity Sensors" in "Humidity Sensors: Types, Nanomaterials and Environmental Monitoring” Ed. C. T. Okada, Nova Science Publishers, (2011), 117-142, ISBN: 978-1-61209-246-1.

[77] C. Ley, I. Calderara, D.J. Lougnot, Meas. Sci. Technol. 8 (1997) 997-1000.

[78] I. Naydenova, V. Toal, "Nanoparticle Doped Photopolymers for Holographic Applications" in "Ordered Porous Solids", Elsevier, 2009. ISBN-13: 978-0-44453189-6.

[79] E. Leite, I. Naydenova, S. Mintova, L. Leclercq, V. Toal, Appl. Opt. 49 (2010) 3652-3660.

[80] E. Leite, J. Phys. Chem. C 114 (2010) 16767-16775.

[81] I. Naydenova, E. Leite, J. Opt. 13 (2011) 044019-044028. 